\title{
Sonographic assessment of petroleum-induced hepatotoxicity in Nigerians: does biochemical assessment underestimate liver damage?
}

\author{
Angel-Mary Anakwue ${ }^{1}$, Raphael Anakwue ${ }^{2}$, Mark Okeji ${ }^{1}$, Felicitas Idigo ${ }^{1}$, Kenneth Agwu', Uloma Nwogu ${ }^{1}$
}

1.University of Nigeria, Enugu Campus, Department of Radiography and Radiological Sciences

2.University of Nigeria, Enugu Campus, Medicine, Pharmacology/Therapeutics

\begin{abstract}
Background: Exposure to petroleum products has been shown to have significant adverse effects on the liver which can manifest either as morphological or physiological changes.

Objectives: The aim of the study was to assess the effects of chronic exposure to some petroleum products on the liver of exposed workers using sonography and to determine whether biochemical assessments underestimated hepatotoxicity.

Methods: Abdominal ultrasound was performed on 415 exposed workers in order to evaluate liver echogenicity and size. Also, biochemical assessment of the liver was done to evaluate its function

Results: Statistically significant increase in the liver parenchymal echogenicity and the liver size was seen in the exposed workers compared with control $(\mathrm{p} \leq 0.05)$. These increased as the exposure duration increased. It was also noted that out of $16.87 \%$ $(\mathrm{N}=70)$ exposed workers with abnormal liver echopattern, only $2.65 \%(\mathrm{~N}=11)$ had alanine aminotransferase above the reference range.

Conclusion: The study revealed evidence of ultrasound detectable hepatotoxicity among the exposed subjects. Sonography appeared to detect petroleum products-induced hepatic toxicity more than biochemical assays suggesting that biochemical assessment may have underestimated toxicity.
\end{abstract}

Keywords: Petroleum Products, Exposure, Hepatotoxicity, Sonography, Biochemical assessment, Nigeria.

DOI: https://dx.doi.org/10.4314/ahs.v17i1.33

Cite as: Anakwue A-M, Anakwue R, Okeji M, Idigo F, Agwu K, Nwogu U. Sonographic assessment of petroleum-induced hepatotoxicity in Nigerians: does biochemical assessment underestimate liver damage? Afri Health Sci. 2017;17(1): 270-277. bttps://dx.doi.org/10.4314/abs. $v 17 i 1.33$

\section{Introduction}

Petrol (gasoline), diesel and kerosene are frequently used petroleum products for the internal combustion of car engines and for operating machines. They are also used in homes as lighting and cooking fuels. These commodities contain predominantly hydrocarbons and have been reported to have significant adverse health effects ${ }^{1,2}$.

Hydrocarbons and other constituents of petroleum products are metabolised and excreted by the liver and kidneys, and exposure to petroleum products have been reported to cause increase in the cytochrome P-450 de-

\footnotetext{
Corresponding author:

Angel-Mary Anakwue,

University of Nigeria,

Enugu Campus,

Department of Radiography

and Radiological Sciences

Email: angelanakwue@yahoo.com
}

pendent monoxygenase and glutathione S-transferase in the liver ${ }^{1}$. Since kerosene, diesel and petrol consist mainly of hydrocarbons, chronic or frequent exposure to them may affect the liver.

Humans are exposed to these products especially at the filling station while refilling of vehicle. In Nigeria, due to the unreliable public power supply, many homes, offices and businesses rely greatly on small electric generators and liquid fuel-dependent machines for day to day activities. The fuel for operating these machines are purchased and stored in homes and offices where their fumes constitute environmental health hazards especially during refuelling. The use of kerosene in homes as cooking and lighting fuels has further increased the exposure of humans to these products ${ }^{1}$.

In Nigeria, the current trend of locating filling stations in residential areas exposes the residents of those areas to liquid fuel fumes. It has also been noticed that the owners of filling stations attach well designed and built duplexes or bungalows to their filling stations. This also exposes 
the occupants of these apartments to petrol fumes. Apart from these, petroleum products have been abused as therapeutic agents for the treatment of snake bites, convulsion, arthritis, gastro-intestinal disorders and a host of other conditions ${ }^{3}$.

Individuals who are occupationally exposed like those who work in petroleum industries or with petroleum distillates are likely to be more affected than their counterparts who do not work in these industries ${ }^{4}$. Automobile mechanics, petrol station pump attendants and petrol tanker drivers belong to this class of people. Unfortunately, they handle these products without proper protection against their possible harmful effects. ${ }^{5}$

The invasiveness of biopsy in obtaining histological data has limited its use in the evaluation of this workplace hepatotoxicity ${ }^{6}$. Biochemical assessments of the liver function especially the hepatic aminotransferases have remained the most common method of detecting toxicity. Regrettably, it has been shown that alanine aminotransferase (ALT) and aspartate aminotransferase (AST) provide limited sensitivity in evaluating liver toxicity. ${ }^{7,8}$

Given the widespread use and abuse of petroleum products, in a background of increasing burden of chronic liver disease ${ }^{9}$ and in consideration of the invasive nature of histology as well as the low sensitivity and specificity of the serum aminotransferases, there is need for non-invasive, diagnostic tool that could detect and monitor progressive pathological processes in the liver.

Ultrasonography which permits display of detailed anatomy and pathology in the liver with its combination of fine resolution, non-invasiveness, absence of ionising radiation hazard, and portable equipment could make the technique ideal for screening populations at risk ${ }^{10}$ especially as it has correlated well with histological abnormalities of steatosis and fibrosis of non-occupational origin ${ }^{6}$ The study therefore seeks to assess the effects of chronic exposure to some petroleum products on the liver of exposed workers using sonography and to assess also the possibility of underestimation of effects by enzyme assessments.

\section{Methods}

This cross sectional study was carried out on 415 adult human subjects of Nigerian origin and aged between 20 and 65 years who gave consent to the study. These included 164 petrol station attendants, 175 automobile me- chanics and 76 petrol tanker drivers. All subjects recruited have been on the job for 5 years and more.

Four hundred and fifteen apparently healthy unexposed subjects of the same age range, who were not engaged in activities that apparently predisposed them to serious contact with petroleum distillates or solvents of any kind, and have been in their occupation for 5 years and above were recruited as controls for the study. This group was drawn from shop attendants and traders in Ogbete and Kenyatta markets in Enugu metropolis because of the close nature of their socio-economic classes. All subjects were males.

Written informed consent was obtained from all the participants and ethical approval was given by the University of Nigeria Teaching Hospital Enugu. Questionnaire regarding the age, socio-economic status, health status, duration of stay and hygiene among others were issued. The weight of each subject was assessed using an analogue scale and height was measured using a portable stadiometer. Using these data, Body Mass Index (BMI) was calculated.

Subjects with the following conditions were excluded from the study: (1). Chronic alcoholism: defined by Elia ${ }^{11}$ as intake of more than 3 units (i .e 11/2 bottles) daily for males and 2 units (1 bottle) daily for females: 1 to 2 units for females and 2 to 3 units for males is normal. (1 unit of alcohol $=8$ grams). (2). Raised blood pressure (hypertension) defined as blood pressure of $140 / 90 \mathrm{mmHg}^{12}$ prior to exposure to petroleum products. (3). Diabetes mellitus defined as blood sugar level above $126 \mathrm{mg} / \mathrm{dl}$ (fasting plasma glucose) or 2 hour plasma glucose $\geq 200$ $\mathrm{mg} / \mathrm{dl}^{13}$ prior to exposure to petroleum products. (4). Abuse of illicit drugs. (5). Cigarette smoking in the past three months. (6). Use of herbal drugs in the past three months. (7) Positive hepatitis B, C and HIV I and II Serology and (8). Obesity defined as BMI $>28.6 \mathrm{~kg} / \mathrm{m}^{2}$ in females and $>30 \mathrm{~kg} / \mathrm{m}^{2}$ in males ${ }^{11}$.

Ultrasound examinations of the liver were performed using a Siemens Sonoline LX unit with a $3.5 \mathrm{MHz}$ linear transducer. This was done to assess the liver echogenicity and size. Standard technique for scanning the liver was followed as described by previous authors ${ }^{14,15}$. All subjects received nothing by mouth for 6 hours before the examination.

The following parameters were documented: (1) liver size, (2) beam penetration, (3) echogenicity, and (4) ancillary abnormality. Using these parameters, the presence 
of diffuse parenchymal disease was identified. Ultrasonographic findings were then analyzed according to the following classification described by Lessa et al: ${ }^{16}$

a. Changes in the liver echogenicity, classified into four patterns: (1) homogeneous liver parenchyma with medium level echogenicity and a regular hepatic surface; (2) diffusely increased parenchymal echogenicity, decreased visualization of the diaphragm and small peripheral vessels in the liver with no change on liver surface; (3) discrete coarse and heterogeneous parenchymal echogenicity, dotted or slightly irregular liver surface; (4) extensive coarse and heterogeneous parenchymalechogenicity, irregular or nodular hepatic surface reflecting the presence of underlying regenerative nodules;

b. Inversion of the sonographic relationship between the liver and the renal cortex. This finding was considered to be positive if the echogenicity of the liver parenchyma was greater or equal to that of the right renal cortex; Mild steatosis was recognised by a slight increase in liver echogenicity, a slight exaggeration of the hepatorenal echo difference with relative sparing of the portal vein markings and diaphragm.

Moderate steatosis was determined by moderately generalised increase in the hepatic parenchymal echogenicity, mild to moderate masking of the periportal wall echoes especially the peripheral branches, which leads to poor visualisation of the diaphragm, greater posterior beam attenuation and greater difference between hepatic and renal echoes.

Severe steatosis was characterised by severe increase in fine echoes in the hepatic parenchyma, greater reduction in beam penetration leading to poor or no visualization of the posterior portion of the right lobe, masking of most of the portal vein wall including the main branches and marked difference between hepatic and renal echoes. The size of the liver was measured in the right Mid-clavicular Line (MCL) with measurement from the hepatic dome to the inferior hepatic tip according to the method described by Börner et $a 1,{ }^{17}$. The first two authors performed the scan independently and their results compared. Where discrepancies existed, author 3 was invited to scan. Complete agreement between Author1 and 2 was obtained in 405 subjects $(97.5 \%)$.

To assess their liver function, specifically, alanine aminotransferase (ALT) and aspartate aminotransferase (AST) and alkaline phosphatase using (ALP), blood was collected from the study participants by standard venopuncture technique. The quantitative colorimetric determination of AST in serum was done by the method based on the modification of the colorimetric method by Doumas and Briggs 18 while the ALT activity was determined using a method based on the modification of the classical Reitman and Frankel colorimetric endpoint reaction. Alkaline phosphatase activity in serum was determined by colorimetric endpoint procedure, using the method described by Roy ${ }^{19}$.

The data were analysed using SPSS version 16.0

\section{Results}

The exposed and control groups were comparable in age, height, weight, BMI and all life style factors as shown in Table 1 . The ages of the subjects and controls ranged from 20 years to 65 years with a mean age of $38 \pm 12$ years for the subjects and $37 \pm 11 \mathrm{yrs}$ for the controls. The mean length of exposure was $11 \pm 6.7$ years and $10 \pm 7.2$ years for the subjects and controls. Apart from the petrol tanker drivers, the subjects spend about 10 hours daily on the average in their places of work. 
Table 1: Demograhic characteristics of the study group compared with their controls.

\begin{tabular}{lll} 
Parameter & $\begin{array}{l}\text { Exposed } \\
\mathbf{n}=\mathbf{4 1 5}\end{array}$ & Unexposed \\
AGE (Years) & $38 \pm 12$ & $\mathbf{n}=\mathbf{4 1 5}$ \\
$\begin{array}{l}\text { Exposure duration } \\
\text { (Years) }\end{array}$ & $11 \pm 6.7$ & $37 \pm 11$ \\
Hours of exposure per day & $10 \pm 0.96$ & $10 \pm 7.2$ \\
$\begin{array}{l}\text { Height } \\
\text { (m) }\end{array}$ & $1.73 \pm 0.058$ & $9 \pm 3.23$ \\
$\begin{array}{l}\text { Weight } \\
\text { (kg) }\end{array}$ & $68 \pm 6.60$ & $1.71 \pm 0.083$ \\
BMI & $22.83 \pm 1.272$ & $67 \pm 5.90$ \\
\hline
\end{tabular}

All values are means SDs

Sonographic assessment of the liver showed that there was increased prevalence of hepatic parenchymal echogenicity (fatty liver changes) among the subjects. This in- crease in hepatic echogenicity was statistically significant and was seen in $70(16.87 \%)$ of exposed workers compared with only $9(2.17 \%)$ of control $(\mathrm{p} \leq 0.05)$ as shown in Table 2.

Table 2a: The liver echogenicity of chronically exposed workers and comparison with their control

$\begin{array}{llll}\text { Category } & \begin{array}{l}\text { Normal } \\ \text { Echogenicity }\end{array} & \begin{array}{l}\text { Abnormal } \\ \text { Echogenicity }\end{array} & \text { Total } \\ \text { Exposed } & 345 & 70 & 415 \\ \text { Control } & 406 & 9 & 415 \\ \text { Total } & 751 & 79 & 830\end{array}$

The effect of petrol on the liver echogenicity is depicted in this table and it showed that more echotextural abnormalities were noted among the exposed group.

Table 2b: Degree of liver echotextural alterations in workers exposed chronically to petrol compared with their control

\begin{tabular}{llllll}
\hline Category & $\begin{array}{l}\text { Normal } \\
\text { Echotexture }\end{array}$ & $\begin{array}{l}\text { Mild } \\
\text { Alteration }\end{array}$ & $\begin{array}{l}\text { Moderate } \\
\text { Alteration }\end{array}$ & $\begin{array}{l}\text { Marked } \\
\text { Alteration }\end{array}$ & Total \\
\hline Exposed & 345 & 25 & 29 & 16 & 415 \\
Unexposed & 406 & 8 & 1 & 0 & 415 \\
Total & 751 & 33 & 30 & 16 & 830 \\
\hline
\end{tabular}

Table $2 \mathrm{~b}$ depicts the degree of echotextural alteration among the study group and the control group. The greatest proportion of subjects with echotextural abnormality had moderately altered liver echotexture. 
The prevalence of, and the severity or degree of the increased liver echogenicity (whether mild, moderate or marked) in the exposed were higher as the duration of exposure increased as shown in Table 3.

Table 3

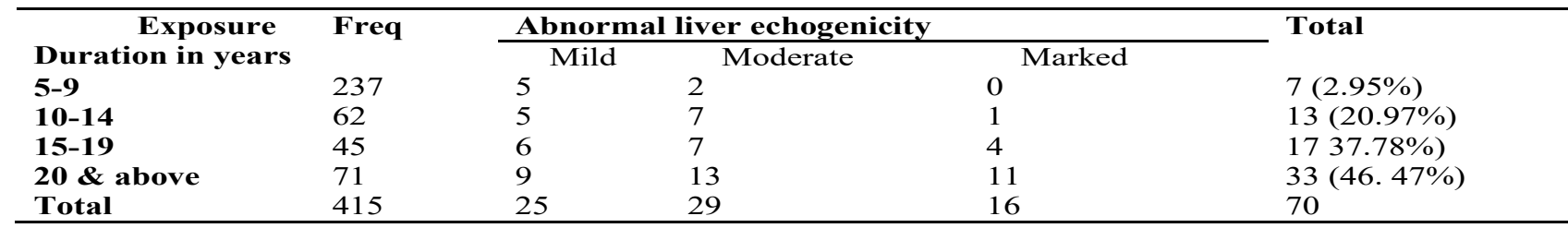

The liver damage appeared to increase as the exposure duration increased as depicted in Table 3

Statistically significant increase $(\mathrm{p} \leq 0.05)$ in the liver size was also noted among the exposed workers compared to the control $(151 \pm 0.61 \mathrm{~mm}$ Vs $140 \pm 0.56 \mathrm{~mm}$ respectively) as shown in Table 4.

Table 4: Liver dimension of the study subjects compared to the control

$\begin{array}{lll}\text { Category } & \text { Liver size(mean+/- SD) } & \text { Range } \\ \text { Exposed } & 151 \pm 0.61 \mathrm{~mm} & 121-180 \mathrm{~mm} \\ \text { Unexposed } & 140 \pm 0.56 \mathrm{~mm} & 102-166 \mathrm{~mm}\end{array}$

Table 4 shows that the mean dimension of the liver in the exposed workers is greater than that in the unexposed control.

One in 5 or $23.37 \%$ of the exposed workers and $1.92 \%$ of the controls had liver dimensions greater than $160 \mathrm{~mm}$. The mean values of the aminotransfareses and Alkaline phosphatase in the study subjects and the controls are depicted in Table 5. These values were within the reference ranges in the exposed workers and control group. However comparison of the values in the exposed and values in the control revealed statistically significant increase in the mean values of the serum hepatic aminotransferases and alkaline phosphatase in exposed as shown in table 5. It was noted that among the exposed group, eleven had ALT value above the reference range while only one was noted among the control group.

It was also observed that out of $16.87 \%(\mathrm{~N}=70)$ exposed workers with abnormal liver echopattern, only $2.65 \%$ $(\mathrm{N}=11)$ had abnormal alanine transaminase..

\section{Discussion}

Petroleum products are known hepatotoxicants, causing increase in hepatic aminotransferases ${ }^{3}$. This type of petroleum product induced-hepatotoxicity detectable by biochemical assessment is well described, but the sonographic findings in the liver in chronic exposure are not well studied particularly in the black African population. Chronic exposure to these products led to increase in he- patic echogenicity documented in this study. Our findings are in agreement with findings of other researchers ${ }^{6,7,8}$. The subjects and controls have the same demographic and anthropometric characteristics as well as socio-economic status including lifestyle factors. Therefore the observed increase in echogenicity of the liver may be attributed to exposure to petroleum products.

This work, as with other works ${ }^{2,5}$, also showed that the longer the subjects were exposed to the products, the more the effects on liver and more the severity ofthese effects. The findings of this study showed that there was increased prevalence of steatosis as well as the severity, as the exposure duration increased.

Despite the non availability of specific histological information regarding the sonographic changes found in this study, there are reasons that suggest that they represent steatosis. These include the strong association of increased hepatic echogenicity with fatty change and reports that fatty change has also been found consistently in histological samples from workers exposed to hydrocarbon $^{6,20}$. Biopsies were not considered in this study due to ethical issues.

Findings of this work are in agreement with the work of Sia et $\mathrm{a}^{17}$ who studied the prevalence and risk factors of 
chronic liver disease among refinery workers. Their findings also showed fatty liver disease (FLD) to be the most common finding. Dossing et $\mathrm{al}^{21}$ reported similar findings of marked steatosis in 11 of 156 subjects exposed to organic solvents for prolonged periods. In experimental models, Lessa et $a{ }^{16}$ described steatosis in the liver of rats exposed chronically to hydrocarbon.

There was also evidence of petroleum-induced hepatomegaly. The average diameter obtained at the right midclavicular line $( \pm S D)$ in the study group was $151 \mathrm{~mm}$ $+/-0.61 \mathrm{~mm}$ (range, $121-180 \mathrm{~mm}$ ). This finding showed a statistically significant difference $(p<0.0001)$ when compared with that of the control group. The mean longitudinal dimension in this group was $140+/-0.56 \mathrm{~mm}$ (range, $102-166 \mathrm{~mm}$ ). Researchers in this field have documented $140 \mathrm{~mm}$ as the mean liver diameter measured in the right midclavicular line (MCL) 22,23,. On the basis of their results, they suggested that a sonographic finding of a liver diameter of $160 \mathrm{~mm}$ or greater in the right MCL should be considered consistent with enlargement of the liver. In this work, $23.37 \%$ of the exposed participants had a liver diameter of greater than $160 \mathrm{~mm}$ compared to $1.92 \%$ noted among the unexposed control group.

The increase in liver diameter noted in this work is possibly as a result of chronic exposure to petroleum products. These products may have led to the accumulation of vesicles of fats or fatty acids especially the triglycerides in liver cells leading to steatosis (or fatty liver disease) and increasing liver size. Exposure to gasoline has been shown to increase the liver size in experimental models ${ }^{24}$ and fatty infiltration has been documented as one of the major causes of hepatomegaly ${ }^{23}$.

The increase in liver size observed in this study may be attributed to the increased prevalence of fatty liver disease associated with chronic exposure to low level petroleum products as fatty liver is known to increase liver size ${ }^{23}$. It therefore follows that individuals exposed to petroleum-based liquid fuel may have enlarged liver.

The study also noted elevation in the mean values of the hepatic amino transferases among the exposed workers. Chronic exposure to these products must have led to the increase in hepaticaminotransferases as the mean values in the exposed differed significantly compared to the control. This finding is in accord with the findings of other researchers $3,6,8$

The increase in the serum levels of these parameters is a sign of liver injury or dysfunction ${ }^{25}$. This is because when

African Health Sciences Vol 17 Issue 1, March, 2017 there is liver damage, enzymes and other metabolites escape from the cellular compartment into the extracellular fluid resulting in the increase in the concentrations ${ }^{25}$.

It was also observed from the study that there were more hepatic abnormalities noted with ultrasonographic imaging compared to biochemistry, specifically, abnormal aminotransferases. That is to say that there were hepatic effects with ultrasonographic imaging in the absence of raised transaminases. Seventy (70) workers had abnormal ultrasound liver appearances while only 11 (eleven) workers were noted to have increase of ALT above the reference level in this work.

These findings agree with the findings of Brodkin et $\mathrm{al}^{6}$. As in the findings of this study, these authors found hepatic effects with ultrasonography in the absence of increased aminotransferases. They reported that serum ALT activity (in only 19\% of their study subjects) underestimated prevalence of hepatic parenchymal changes as determined by sonography (in 32\% of their study subjects). They concluded that their findings suggest that aminotransferases may be of limited use in detecting subclinical injury preceding the occurrence of prominent inflammation or necrosis. Sia et $\mathrm{al}^{8}$ also observed that about half of the oil refinery workers that had fatty liver detected by ultrasound in their work were not detected by the criterion of elevated ALT and that fatty change on sonograms was noted in one-fifth of those with normal ALT blood level.

The observation that there were ultrasound-detectable hepatic effects in the presence of normal aminotransferases implies that morphological alteration may have preceded the raise in hepatic aminotransferases. This finding suggests that assessment of liver injury with only hepatic aminotransferases may underestimate hepatotoxic effects of hydrocarbon in exposed workers. It also suggests that hepatic imaging with ultrasound may be a useful tool for assessing preclinical hepatic effects of chronic exposure to hydrocarbons. Additionally, other studies comparing sonographic findings and aminotransferases have reported similar reduction in sensitivity and specificity. ${ }^{6,8}$. These authors have questioned the effectiveness of aminotransferases because of their low sensitivity and specificity. In addition, fatty liver disease, which may be present despite normal liver function tests, has been linked to solvent exposure during house painting and a variety of other occupations $^{26,27}$. The conclusion is that significant hepatotoxicity may occur without causing any enzyme abnormality. 
Poor handling of petroleum products may have contributed to the global increase in hepatic diseases. This is particularly worse for developing countries like Nigeria where filling stations are located indiscriminately in living quarters in addition to the high rate of abuse. Moreover,the population at risk are not aware of the need to example, automobile mechanics use petrol in washing automobile parts and for hand-washing especially after working with greased vehicle or equipment parts. They also stand a risk of swallowing small amounts of fuel during siphoning of fuel from car fuel tanks.

This is unsettling because there is a growing concern that FLD may be a contributory in the development of hepatic fibrosis and that a few of the subjects may progress to liver failure ${ }^{28,29}$. In recent studies, FLD seems to contribute to the metabolic syndrome, which includes type 2-diabetes, dyslipidemia, obesity and hypertension ${ }^{30,31}$.

The exposure to petroleum products in Nigeria has many that make people take jobs that expose them unduely to petroleum toxicants, stark ignorance of the exposed population and even majority of the health workers, the lack of occupational health laws and the inability to implement few existing industrial effluent regulations due to corruption. It has been documented in Nigeria, that treatment of snake bites, arthritis, convulsion and gastro-intestinal disorders among others ${ }^{2}$. These taken together with increase in the prevalence of Liver diseases in Nigeria have made exposure to petroleum products an important area of study.

The major limitation of this work is the inability to compare sonographic findings with histological information. There is also need to investigate the effect of exposure dose on the liver of exposed workers.

\section{Conclusion}

The study confirmed that exposure to petroleum products could cause increased level of aminotransferases, hepatomegaly and increased liver echogenicity. It also demonstrated that ultrasonography is not only a useful tool for identifying petroleum product induced hepatotoxicity but may be more sensitive biochemical assessments in assessing liver toxicity.

The authors declare that there are no conflicts of interest. protect themselves or handle these products carefully. For dimensions given the poverty pervading in the country petroleum products are used as therapeutic agents for the

\section{Conflict of interest:}

\section{References}

1. Uboh FE, Akpanabiatu MI, Ebong PE, Eyong EU, Eka OU. Evaluation of toxicological implication of inhalation exposure to kerosene and petrol fumes in rats. Acta Biol Sreged.; 2005 49:19-22.

2. Nwanjo HU, Ojiako C, Investigation of the Potential Health Hazards of Petrol Station Attendants in Owerri Nigeria J. Appl. Sci. Environ. Manage. 2007;11 (2) 197 200.

3. Patrick-Iwuanyanwu KC, Onyemaenu CC, Wegwu MO, Ayalogu EO. Hepatotoxic and Nephrotoxic effects of kerosene and petrol contaminated diets in Wistar Albino rats. Res J Environ. Toxicol, 2011; 5: 49-57.

4. Okoro AM, Ani EJ,Ibu JO, Akpogomeh BA. Effect of petroleum products inhalation on some haematological indices of fuel attendants in Calabar metropolis, Nigeria. Niger J Physiol Sci. 2006: 21; (1-2):71-5.

5. Udonwa NE, Uko EK, Ikpeme BN, Ibanga IA, and Okon BO. Exposure of Petrol Station Attendants and Auto Mechanics to Premium Motor Sprit Fumes in Calabar, Nigeria. Journal of Environmental and Public Health, 2009, Article ID: 281876, 5 pages. doi: 10.1155/2009/281876.

6. Brodkin CA, Daniell W, Checkoway H, Echeverria D, Johnson J, Wang K: Hepatic ultrasonic changes in workers exposed to perchloroethylene. Occup Environ Med. 1995;52: 679-85.

7. Sia H., Wang J, Huang C, Huang C. Prevalence and Risk Factors of Chronic Liver Disease among Oil Refinery Workers. J Occup Health. 2002; 44: 22-27

8. Sia H., Wang J, Huang C, Huang C. Serum Alanine Aminotransferase as an Annual Screening Tool for Diseases Among Workers. Changhua J Med. 2004; 9: 122-27

9. Lim YS and Kim WR. The global impact of hepatic fibrosis and end-stage liver disease. Clin Liver Dis. 2008 Nov;12(4):733-46, vii. doi: 10.1016/j.cld.2008.07.007. 10. Taylor KJ, Williams DM, Smith PM, Duck BW. Greyscale ultrasonography for monitoring industrial exposure to hepatotoxic agents. Lancet. 1975 31; 1(7918):1222-4.

11. Elia M. Nutrition. In: Clinical Medicine. (Eds. Kumar P and Clark M) Edinburgh: Elsevier Saunders. 2005 6th ed, p 255-263.

12. Onwubere BJC. Essentials of Hypertension management. Institute of Development Studies UNEC Enugu. $2005 \operatorname{Pg} 3$

13. Gale EAM and Anderson JV. Diabetes mellitus and other disorders of metabolism. In Clinical Medicine. (Eds. Kumar P and Clark M) Edinburgh: Elsevier Saunders. 2005 6th ed, p 1101-1151. 
14. Sanders RC, Miner NS: Right upper quadrant mass. In: Clinical Sonography; A Practical Guide 2nd ed. Boston/Toronto/London, Little, Brown and Company, 1991 p 213-239.

15. Palmer P ., Manual of diagnostic ultrasound World Health Organization Geneva 1995; 152-155

16. LessaAS, Paredes BD, Dias JV, Carvalho AB, Quintanilha LF, Takiya CM, et al. Ultrasound imaging in an experimental model of fatty liver disease and cirrhosis in rats. BMC Veterinary Research 2010, 6:6doi:10.1186/17466148-6-6

17. Borner N, Schulerk WB, Braun B. Leber. In: Braun B, Gunther R, Schwerk WB (eds). Ultraschalldiagnostik. Landsberg, Bermany: Ecomed; 1987:1-18.

18. Doumas B, Briggs H. Clin. Chem. Acta 1969; 25:75 19. Roy A.V., Rapid method for determining alkaline phosphatase activity in serum with thymolphthalien monophosphate. Clinical Chemistry. 16: 4311970

20. Lundqvist G, Flodin U, Axelson O. A case-control study of fatty liver disease and organic solvent exposure. Am J Ind Med. 1999; 35:132-6.

21. Dossing M, Arlien-Soborg P, Petersen LM, Ranek L . Liver damage associated with occupational exposure to organic solvents in house painters. Eur J Clin Invest; 1983. 13:151-7.

22. Kratzer W, Fritz V, Mason R, Haenle M, Kaechele $\mathrm{V}$, and the Roemerstein Study Group Factors Affecting Liver Size J Ultrasound Med. 2003 22:1155-1161, 23. Krebs CA, Giyanani VL, Eisenberg RL . Ultrasound atlas of Disease Processes. Appleton and Lange Norwalk Connecticut USA1993 36-38
24. Uboh FE, Akpanabiatu MI, Ndem JI, Alozie Y, Ebong PE. . Comparative nephrotoxic effect associated with exposure to diesel and gasoline vapours in rats. Journal of Toxicology and Environmental Health Sciences. 2009;1 (3) 68074.

25. Uboh FE, Akpanabiatu MI, Eteng MU, Ebong PE, Umoh IB . Toxicological Effects of Exposure to Gasoline Vapour in Male and Female Rats. The Internet Journal of Toxicology. 2008;4:2.

26. Rees D, Soderlund N, Cronje R, Song E, Kielkowski D, Myers J. Solvent exposure, alcohol consumption and liver injury in workers manufacturing paint. Scandinavian Journal of Work Environmental Health. 1993;19:236- 44.

27. Neghab M, Stacey NH : Serum bile acids as a sensitive biological marker for evaluating hepatic effects of organic solvents. Biomarkers. 5:81-107.

28. Hodgson M, van Thiel DH, Goodman-Klein B (1991). Obesity and hepatotoxins as risk factors for fatty liver disease. $\mathrm{Br} I$ Ind Med; 2000; 48:690-5.

29. Marchesini G, Forlani G. NASH: from liver diseases to metabolic disorders and back to clinical hepatology. Hepatology; 2002;35:497-9.

30. Chitturi S, Abeygunasekera S, Farrell GC, Holmes-Walker J, Hui JM, Fung C: NASH and insulin resistance: insulin hypersecretion and specific association with the insulin resistance syndrome. Hepatology; 2002; 35:373-9.

31. Pagano G, Pacini G, Musso G, Gambino R, Mecca F, Depetris $N$ : Nonalcoholic steatohepatitis, insulin resistance, and metabolic syndrome: further evidence for an etiologic association. Hepatology; 2002; 35:367-72. 